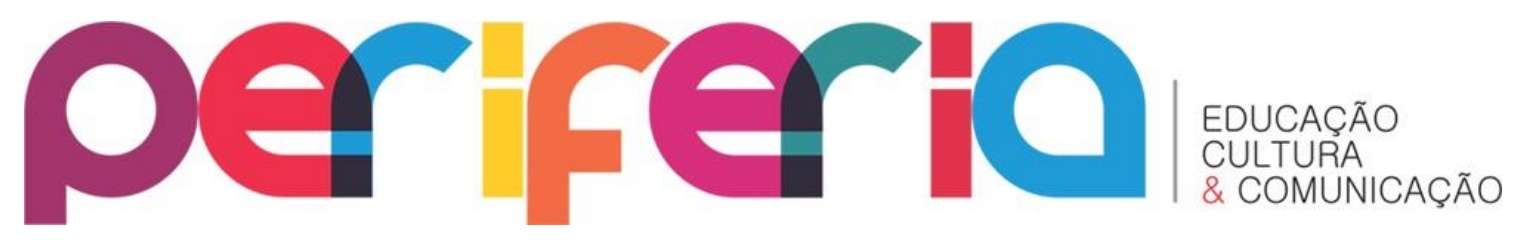

\title{
MULHERES COMO PROTAGONISTAS NA POLÍTICA: A REPRESENTATIVIDADE DA MULHER NA POLÍTICA DA BAIXADA FLUMINENSE - DUQUE DE CAXIAS E MAGÉ, RJ, BRASIL.
}

\author{
Lohane Cristina de Castro Dantas ${ }^{1}$ \\ Universidade do Estado do Rio de Janeiro - UERJ \\ Maria Clara Moreira do Santos ${ }^{2}$ \\ Universidade do Estado do Rio de Janeiro - UERJ \\ Isabelle Jesus Teixeira do Nascimento ${ }^{3}$ \\ Universidade do Estado do Rio de Janeiro - UERJ \\ Tatiane Pinheiro Cacimiro 4 \\ Universidade do Estado do Rio de Janeiro - UERJ
}

\section{Resumo}

A temática deste trabalho surge a partir da necessidade de fazer um panorama histórico da mulher na política da Baixada Fluminense, Rio de Janeiro, dando ênfase a dois municípios específicos, Duque de Caxias e Magé. Trata-se de um ensaio etnográfico apresentado à professora Rosangela Malachias, que lecionou a disciplina Cultura Local e Global, na Faculdade de Educação da Baixada Fluminense. $O$ trabalho foi selecionado para integrar as comunicações da 6th WLE Conference, Brazil, 2017. No ano de 2016, tivemos como marco histórico e político o impeachment de Dilma Rousseff, a primeira mulher a assumir a presidência do Brasil. Pensando nesse cenário e no quanto ainda no século XXI, dentro de uma sociedade patriarcal. 0 fato de uma mulher ser protagonista no meio político e ocupar cargos de responsabilidades e poder, apresenta constrangimentos e incompatibilidade com as representações femininas persistentes na sociedade brasileira. Decidimos estudar a representatividade das mulheres na política, apresentando um estudo de caso com recorte regional - a Baixada Fluminense, região famosa por ter família inteiras no meio político e possuir um caráter extremamente conservador e patriarcal. A Baixada Fluminense é uma região composta por treze municípios, a princípio escolhemos apenas um deles para trabalhar, devido a localidade da Faculdade de Educação

\footnotetext{
1 Graduanda de Licenciatura em Pedagogia, na Universidade do Estado do Rio de Janeiro Faculdade de Educação da Baixada Fluminense (UERJ/FEBF). lohanee.castroo@gmail.com

${ }^{2}$ Graduanda de Licenciatura em Pedagogia, na Universidade do Estado do Rio de Janeiro Faculdade de Educação da Baixada Fluminense (UERJ/FEBF). mariamoreiraclara@gmail.com

3 Graduanda de Licenciatura em Pedagogia, na Universidade do Estado do Rio de Janeiro Faculdade de Educação da Baixada Fluminense (UERJ/FEBF). isabellenascimento@hotmail.com

${ }^{4}$ Graduanda de Licenciatura em Pedagogia, na Universidade do Estado do Rio de Janeiro Faculdade de Educação da Baixada Fluminense (UERJ/FEBF). tatianecacimiro@gmail.com
}

Periferia, v. 10, n. 2, p. 203-216, jul./dez. 2018 


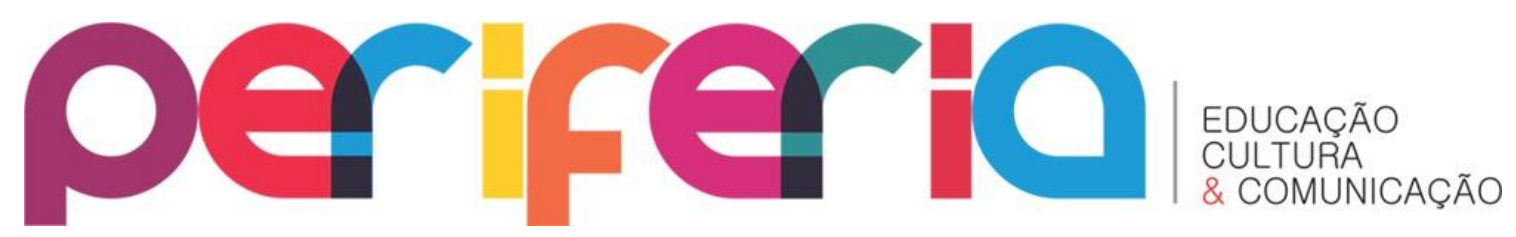

da Baixada Fluminense, situada em Duque de Caxias, por haver um interesse em conhecer melhor a história política da cidade, além dos personagens masculinos e já famosos. Nossa intenção é analisar se na política deste município houve participações femininas além das secretárias e cargos comissionados, como foi o caminho até chegarem ao posto que conquistaram através do voto direto e como foi para continuarem assumindo o cargo que lhes fora confiado pela população da cidade. No final do trabalho, esperamos ter conseguido mostrar uma linha histórica da presença das mulheres na política da cidade de Duque de Caxias, fazendo uma análise também com o período histórico e as explosões de identidades.

Palavras-chave: mulheres; política; representatividade; Baixada Fluminense 


\section{periferio}

PROTAGONIST WOMEN IN POLITICS:

THE REPRESENTATIVENESS OF WOMEN IN POLITICS IN THE

BAIXADA FLUMINENSE - DUQUE DE CAXIAS, RJ, BRAZIL

\section{Abstract}

The thematic of this work arises from the necessity to make a historical view of the woman in the politics of the Baixada Fluminense, Rio de Janeiro. Giving emphasis to one specific municipalities, Duque de Caxias. This is an ethnographic essay presented to teacher Rosangela Malachias, who taught the Local and Global Culture discipline ate the Baixada Fluminense School of Education. The work was selected to integrate to communications from the 6th WLE Conference. In 2016, we had as a historical and political landmark the impeachment of Dilma Rousseff, the first woman to assume the presidency of Brazil. Thinking about this scene and how much still in the 21st century, within a patriarchal society. The fact that a woman being protagonist in the political environment and occupying positions of responsibility and power, presents constraints and incompatibilities with the persistent female representations in Brazilian society. We decided to study the representativeness of women in politics, presenting a case study with a regional cut - the Baixada Fluminense, a region famous for having an entire family in the political environment and having an extremely conservative and patriarchal character. The Baixada Fluminense is a region made up of thirteen municipalities. At first we chose only one of them to work, due to the locality of the Baixada Fluminense School of Education, located in Duque de Caxias, because there is an interest in knowing better the political history of City, in addition to the male and already famous characters. Our intention is to analyze if in the politics of this municipality there were women's participation besides the secretaries and positions commissioned, as was the way to reach the post they conquered through direct voting and how it was to continue assuming the position entrusted to them by the population of the city. At the end of the work, we hope to have managed to show a historical line of women's presence in the politics of the city of Duque de Caxias, also analyzing the historical period and the explosions of identities.

Keywords: women; politics; representativeness; Baixada Fluminense 




\section{INTRODUÇÃO}

No ano de 2016, tivemos como marco histórico e político o impeachment de Dilma Rousseff, a primeira mulher a assumir a presidência do Brasil. Pensando nesse cenário e no quanto ainda no século XXI, dentro de uma sociedade patriarcal, o fato de uma mulher ser protagonista no meio político e ocupar cargos de responsabilidades e poder ainda parecer incomodar tanto, decidimos estudar, sobre a representatividade das mulheres na política da Baixada Fluminense, região famosa por ter família inteiras no meio político e possuir um caráter extremamente conservador e patriarcal.

Este trabalho tem o objetivo de retratar a presença e das mulheres na política da Baixada Fluminense, dando ênfase a cidade de Duque de Caxias. Utiliza-se como principal referencial teórico Stuart Hall (2002), que em seu livro "A Identidade Cultural da Pós-modernidade" nos dá contribuições importantíssimas para entender o que acontece com algumas dessas mulheres pesquisadas. Hall trata das explosões de identidades no século $X X$, período no qual o feminismo se amplia as mulheres passam a se reconhecer e se empoderar de uma identidade de gênero. Buscamos entender um pouco mais sobre o que talvez norteie as ações políticas das personagens - mulheres na política - Duque de Caxias.

A princípio estava extremamente difícil dar início a uma pesquisa sobre esta temática, que pouco se fala, mas foi através dos artigos de Liandra Lima Carvalho (2015), que conseguimos conhecer duas personagens importantes da história desta cidade, como Claise Maria Zito e Estela Alves Vasconcelos. A análise histórica possibilitou-nos chegar à algumas conclusões que serão expostas neste artigo.

Nossa primeira atitude foi buscar informações através de um meio rápido e acessível para nós, que foi a internet. Lá encontramos algumas informações que nos auxiliaram com a temática, porém ainda não eram suficientes. $\mathrm{Na}$ biblioteca da Faculdade de Educação da Baixada Fluminense, nos deparamos com uma autora chamada Liandra Lima Carvalho. 


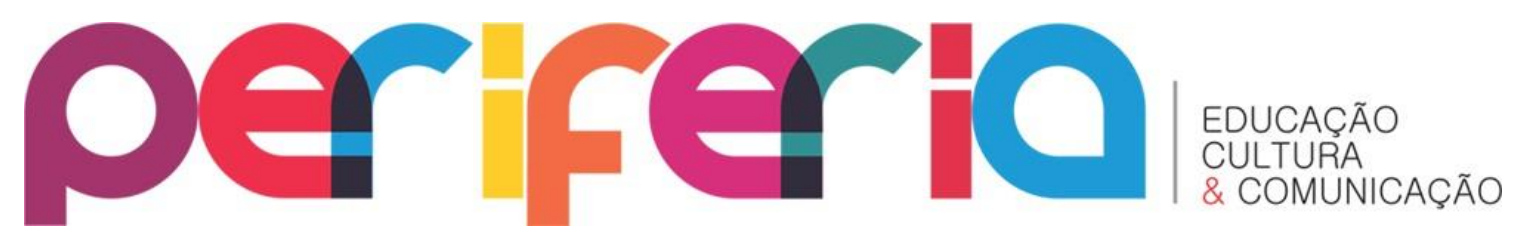

\section{A HISTÓRIA DA PRIMEIRA VEREADORA ELEITA EM DUQUE DE CAXIAS}

Dalva Lazaroni de Moraes, nascida em 07/11/1945 no município de Itaperuna no Estado do Rio de Janeiro. Foi advogada, professora, escritora e política. Casada com o empresário Paulo de Moraes, mãe de três filhos, entre eles o deputado estadual André Lazaroni do PMDB, avó de cinco netos.

Como autora possui mais de trinta obras, entre eles destacam-se $A$ história de Armanda Álvaro Alberto, a qual foi professora de Dalva e de sua irmã Emília, para concretização da obra foram mais de vinte anos de pesquisa, dentre elas estão: Chiquinha Gonzaga; Sofri, chorei; Tive muito amor; Uma galinha carioca da gema; Quilombos e Tiradentes na Baixada Fluminense: Uma homenagem a Solano Trindade.

Como política e grande ambientalista, amiga do ilustre Chico Mendes, foi fundadora do Partido Verde (PV), Primeira Secretária do Meio Ambiente do município de Duque de Caxias, também foi Secretária de Cultura e primeira Vereadora do município de Duque de Caxias, mobilizando forte luta por uma fiscalização forte sobre a Refinaria de Duque de Caxias (REDUC) devido ao grande impacto ambiental gerado na região de Campos Elíseos.

Em 1998, candidatou-se ao Governo do Estado do Rio de Janeiro, chegou ao segundo turno, mas foi derrotada por Anthony Garotinho. Em 2004, candidatou-se a Vereadora do município do Rio de Janeiro, tendo sido eleita primeira suplente, atrás da Aspásia Camargo. Em 2011, filiou-se ao Partido dos Trabalhadores (PT) de Duque de Caxias, inaugurou a Escola de Formação Política Edinha Maia, com a Biblioteca Pública, cursos profissionalizantes e diversas exposições.

Lutou bravamente durante 50 anos contra um câncer linfático falecendo, em 4 de julho de 2016, aos 70 anos, em seu apartamento em Ipanema, Zona Sul da cidade do Rio de Janeiro onde vivia, mesmo cumprindo mandato em Duque de Caxias. Um mês antes da sua morte, Dalva escreve um lindo poema, falando sobre a morte que sentia aproximar-se. 


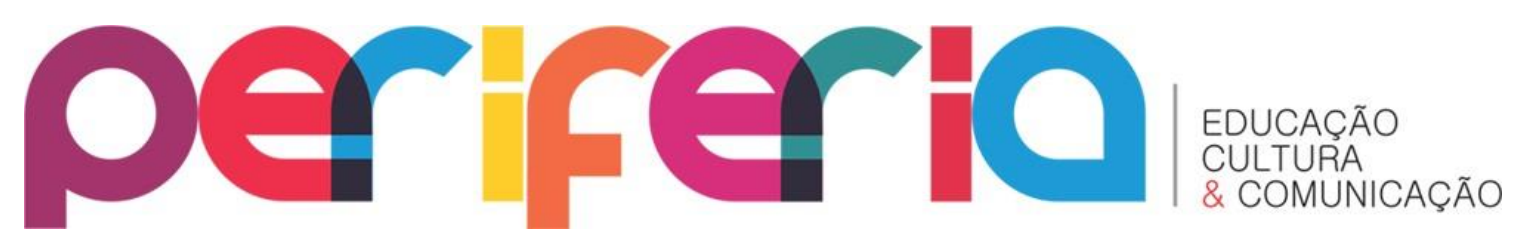

"Meus mortos vivem em mim" Existem aqueles que morrem todos os dias

Outros morrem por antecipação

Há os que morrem aos pouquinhos

Ora por desamor

Ora sem inspiração

Tem gente que morre na ignorância

Também se morre por ignorância

Muitos morrem no orgulho

$\mathrm{Na}$ ânsia da ganância

No gosto do desgosto

A mágoa e a tristeza matam cada vez mais

São frutos da incompreensão

Suicidas se matam nas bebidas

Asfixiados nas fumaças dos cachimbos

$\mathrm{Na}$ toxidade da corrupção

Empurrando a vida pra baixo

Abismo abaixo da infinita solidão

Mas tem gente que simplesmente não morre

Pois vive para sempre em mim Nos que vêm antes de mim

Desses eu sinto saudades

Ainda ouço suas vozes

0 ruído dos seus passos

Vejo-lhes os sorrisos

Sinto seus abraços

Cada um dos seus afagos

A mão

O amparo

Então me vem o pranto

0 pranto do adeus

Também me vem a certeza

De que a semente renasce

A semente renasce pra Deus. (MORAES, 2016)

\section{CLAISE MARIA - PRIMEIRA DEPUTADA ESTADUAL ELEITA POR DUQUE DE CAXIAS}

Claise Maria Zito, a primeira deputada estadual mulher, pelo município de Duque de Caxias antes de conquistar esta posição no meio político, foi secretária na Secretaria Municipal de Assistência Social e Direitos Humanos mantendo uma intensa preocupação com ações políticas voltadas para as mulheres da cidade de Duque de Caxias. 


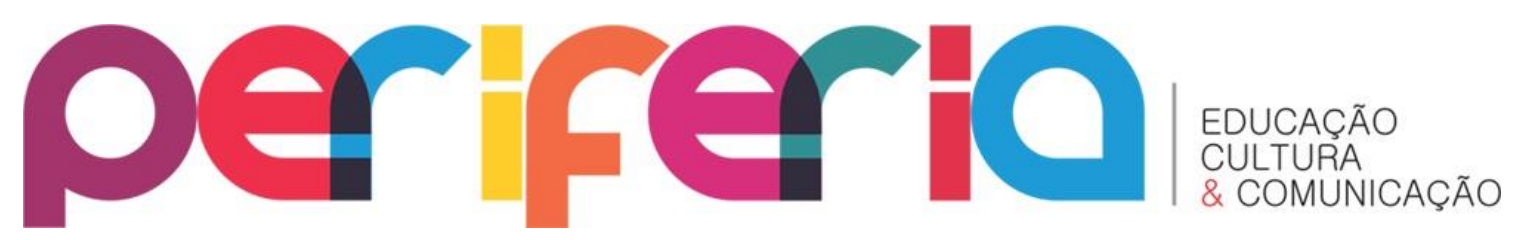

Claise Maria nasceu na Baixada Fluminense, no município de São João de Meriti. Casou-se com José Camilo Zito dos Santos Filho, político conhecido como Zito, em 2005 e assumiu o papel de primeira dama de Duque de Caxias.

Em 2007 Zito, se candidata novamente para a prefeitura de Duque de Caxias, cidade a qual já havia governado, mas nessa campanha em especial, tinha ao seu lado Claise Maria, com quem se casou no final de seu segundo mandato consecutivo como prefeito da cidade.

Zito ganhou as eleições e em 2008 assumiu novamente a prefeitura e logo nomeou Claise, que foi o de secretária geral do Instituto de Previdência do Servidor Público (IPMDC), em 2009 ele a deu o cargo de diretora da Secretária Municipal de Assistência Social e Direitos Humanos (SMASDH).

Claise era formada em professora, pelo curso de formação de professores em nível médio. Começou a cursar matemática, em seguida Direito, mas não concluiu nenhum dos dois cursos. Ao assumir a SMASDH ela reconheceu que só a importância política de seu marido, não a ajudaria em seu trabalho a esta nova secretária de governo, portanto resolveu retornar a universidade e começar a cursar graduação em Serviço Social, para entender melhor a área e visando que esse curso a auxiliasse no seu trabalho, na secretária pela qual era responsável.

Ela participava ativamente da vida política de seu marido e começou a construir relações no meio, já que entendia que só o aparato político de seu marido e o conhecimento teórico da graduação de nada serviria se ela não tivesse contatos no meio político.

Seu trabalho no município, através da SMASDH deu muita importância as questões de gênero no que tange a mulher. Suas ações foram: “[...] estruturação do Departamento dos Direitos da Mulher; o apoio dado ao Conselho Municipal dos Direitos da Mulher, inclusive em relação ao espaço físico; o reconhecimento da atuação do Centro de Referência da Mulher, órgão de atendimento às mulheres em situação de violência doméstica; e a criação da Casa da Mulher Caxiense, voltada para a capacitação profissional das mulheres, através da organização de cursos e oficinas." (CARVALHO, 2015, p. 121) Até mesmo o tema de sua monografia teve uma temática voltada para mulher, que Periferia, v. 10, n. 2, p. 203-216, jul./dez. 2018 


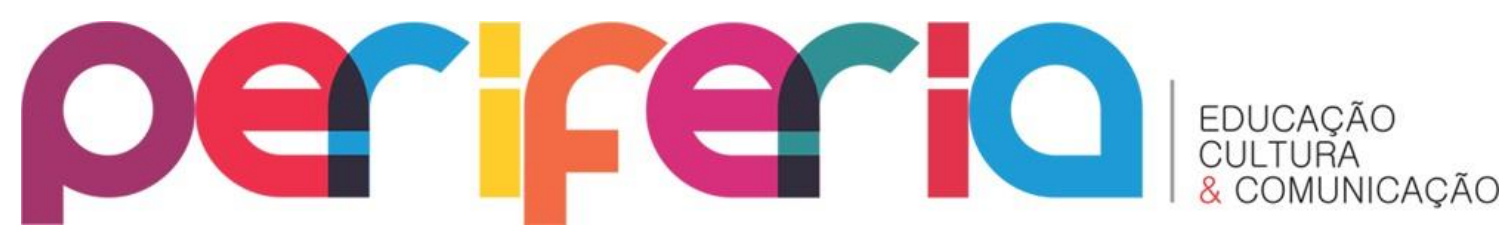

dizia respeito sobre o Centro de Referência de Atendimento a Mulher de Duque de Caxias.

Ao trabalharmos Stuart Hall, notamos que ele traz uma contribuição, que em parte nos leva a entender um pouco, sobre esse processo de representatividade da mulher, enquanto representante das outras. Para nós é como se Claise sentisse que o papel de estar ali era lutar e garantir a voz das mulheres da cidade de Duque de Caxias. Em sua obra "A Identidade Cultural da Pós-modernidade", de 2015, Hall diz assim:

\begin{abstract}
"As/os autoras/es que defendem a ideia de que as identidades modernas estão em colapso usam os principais argumentos: "estamos vivenciando uma estruturação social, que teve início no final do século $X X$; vivenciamos uma fragmentação neste período, nos panoramas: de classe, gênero, sexualidade, etnia, raça e nacionalidade, que no passado eram sólidas; as transformações estão nos levando a questionar o que somos, como nos encaixamos na sociedade e o porque de já nascermos subordinadas a algo. $\mathrm{E}$ todos esses fatores seriam responsáveis por gerar a "crise da identidade." (HALL, 2002, p. 9).
\end{abstract}

Claise ganhou muito destaque com sua atuação na Secretaria, até que o partido começou a conversar sobre a possibilidade dela concorrer como candidata a deputa estadual pelo partido. Seu marido não gostou muito da ideia, mas o partido a convidou e mesmo sem o apoio inicial de Zito, Claise resolve aceitar o convite. Para seu marido, ela não deveria estar estudando e ter aceitado o convite do partido, mas sim ficar em casa tomando conta das coisas. Mesmo sendo contrário a decisão da esposa, Zito apoiou politicamente a campanha dela.

Em 2010, Claise ganhou as eleições, para Deputada Estadual, para atuar como representante da cidade de Duque de Caxias na ALERJ. Foi a única mulher representante da cidade que ganhou e barrou seis adversários, que também concorreram ao mesmo cargo. Neste mesmo período a bancada da ALERJ contava com apenas 13 mulheres, dentre 70 homens.

Durante o seu mandado de Deputada Estadual e após o seu divórcio, Claise Maria sai do PSDB, partido de seu ex-marido e filia-se ao PSD, com a 


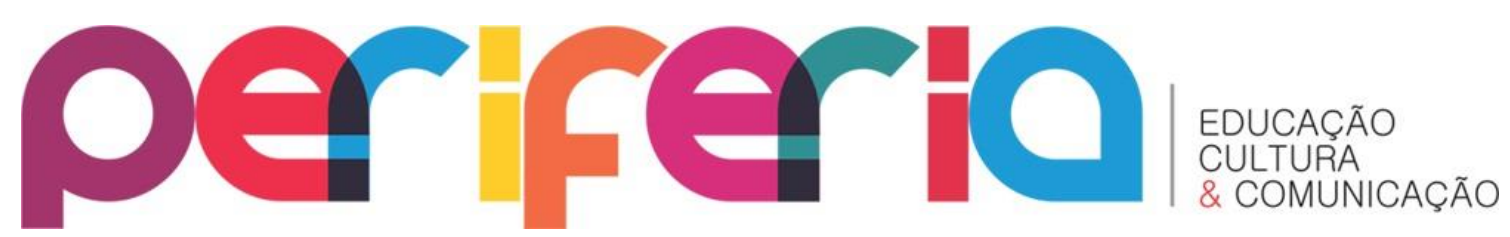

justificativa de que se sentia sozinha na ALERJ e já não se sentia com espaço no PSDB. Em 2014 torna-se presidente do PSD em Duque de Caxias.

Essa mulher não foi para Assembléia Legislativa do Estado do Rio de Janeiro (ALERJ), apenas como um mero enfeite, para garantir ao seu partido uma representatividade feminina, pelo contrário, ela foi muito ativa:

Essa assistente social, especialista em Gestão Pública, ao longo de seu primeiro mandato como deputada estadual foi autora de 65 projetos de Lei 23 e 22 leis 24, atuou como Presidente da Comissão de Assuntos da Criança, do Adolescente e do Idoso, bem como em outras comissões (ALERJ, 2015)" (CARVALHO, 2015, p. 126)

Além disso, ela também fez parte da Frente Parlamentar da Bancada Feminina da ALERJ; foi a primeira mulher a ocupar o posto de secretária da Secretária Estadual de Trabalho e Renda, convidada pelo governador Sérgio Cabral, no ano de 2013, ela assumiu de março a junho de 2013.

Durante toda a sua atuação política, sempre buscou fazer o recorte de gênero e pautar questões de lutas, em relação à vida das mulheres. Nas eleições de 2014, Claise tenta reeleição, para deputada estadual, enfrenta nas urnas o seu ex-marido Zito, mas não sai vitoriosa. Em 2015, é nomeada para a Secretária de Desenvolvimento da Baixada Fluminense, pelo governador Luiz Fernando Pezão.

\section{PRIMEIRA MULHER COMO VICE-PREFEITA DE DUQUE DE CAXIAS}

A primeira vice-prefeita de Duque de Caxias foi Estela Alves Vasconcelos, possuía duas graduações, uma em Pedagogia e outra em Psicologia, e uma especialização em Docência do Ensino Superior. Ela tomou posse aos 58 anos, no ano de 2001, como vice do prefeito José Camilo Zito dos Santos Filho.

$\mathrm{Na}$ década de 90, conheceu o Zito e trabalhou como sua assessora. Criaram uma relação, que chegou a se considerar fraterna, segundo a própria Estela Vasconcelos justificando a escolha de Zito, para que ela fosse a viceprefeita dele: 


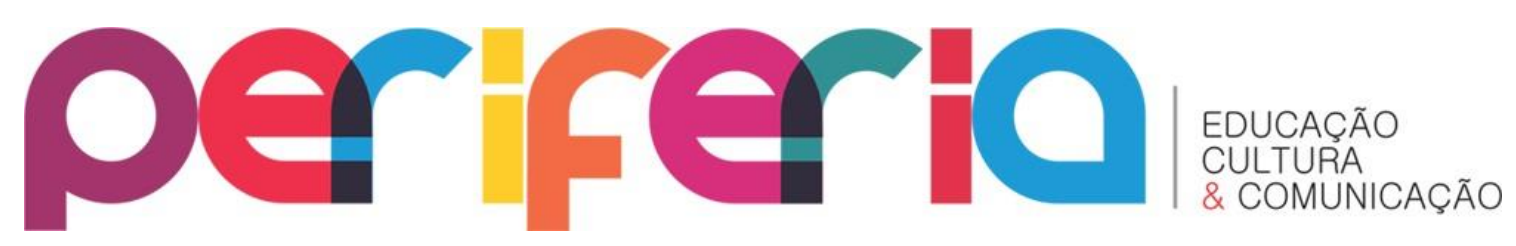

[...] por eu trabalhar, assim, me dedicando com tudo, estando ao lado dele e assim, tempo todo, foi aí que ele falou: "Poxa! [...] Não vou trazer estranho! Eu tenho que trazer uma pessoa que eu possa virar as costas e não ser traído! Não tem outra pessoa a não ser você! (CARVALHO, 2015, p. 58, grifo da autora).

Estela trabalhou 12 anos com o Zito, até ser convidada para ser sua viceprefeita, na disputa por sua reeleição. Trabalhou com Zito na administração de seu Centro Social, localizado no bairro Dr. Laureano, em Duque de Caxias; como sua assessora na Câmara de Vereadores do município e na ALERJ; foi vicesecretária de meio ambiente e secretária de obras, no seu primeiro mandato como prefeito. Seu cargo a vice-prefeita de Duque de Caxias, não foi influenciado por um marido que já tinha alguma participação na política, como foi o caso Claise Maria Zito, que entrou na vida política através de seu ex marido. Uma das maiores organizações que ela gostava era da Festa de Natal da cidade.

Zito incentivou-a retornar seus estudos e ir cursar Administração Pública, ela aceitou o incentivo e foi estudar em Botafogo na Fundação Getúlio Vargas. Moradora de Duque de Caxias, mesmo durante sua atuação enquanto viceprefeita e nas secretárias municipais.

Houve uma pequena possibilidade, de ela assumir os dos últimos anos do mandato de 2002, quando Zito decide junto com um grupo do seu partido que viria como candidato a governador, caso isso acontece, Estela ficaria no seu lugar, mas infelizmente, um grupo de parlamentares do partido acabou com os planos e indicaram outra pessoa, acabando com as esperanças de Estela ser a primeira prefeita de Duque de Caxias.

Estela passa por um momento complicado na vida política, quando um grupo de assessores chegam a Zito falando da ambição dela por poder e alegando que ela desejaria até mesmo a morte dele, para se tornar prefeita. Ele acredita e acaba trocando 15 anos de serviço, parceria e amizade, por essa farsa. 


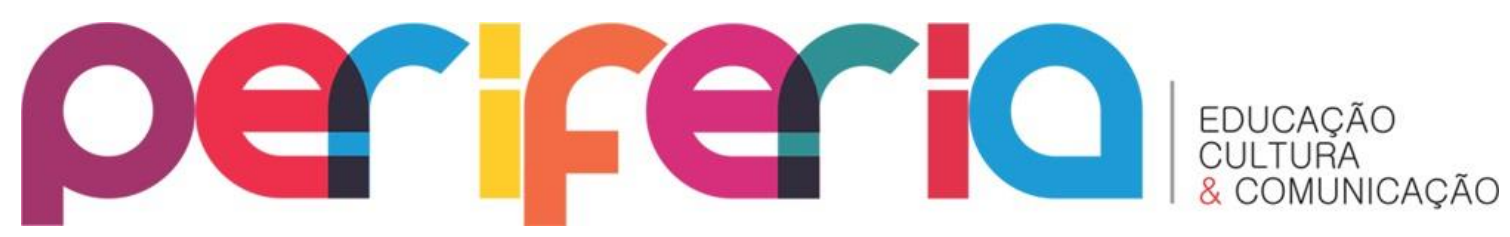

Meses depois Estela decidiu se afastar do cargo de vice-prefeita, devido às intrigas na relação entre ela e Zito. “Em alguns momentos, tive a impressão que estava estudando sobre alguém 'quase invisível', mas que foi a única viceprefeita de um dos maiores municípios da Baixada Fluminense" (CARVALHO, 2015, p. 65).

De fato como dito por Liandra Lima Carvalho, pouco se encontra sobre Estela e sua atuação no meio político, o que também nos gerou dificuldades e foi ai que encontramos um dos artigos da tese de mestrado dela, "Estela, uma Estrela na Política de Duque de Caxias".

\section{PRIMEIRA VICE-PRESIDENTE DE MESA DA CÂMARA MUNICIPAL DE DUQUE DE CAXIAS}

Juliana Fant Alves, ou Juliana do Táxi como ficou conhecida em Duque de Caxias, foi candidata a vereadora em Duque de Caxias, ela é filha de um ex vereador, Sebastião de Souza Alves, conhecido na vida política como Tião do Táxi e possuí ensino superior completo.

Ela entrou na política através da influência do seu pai e acabou conseguindo se manter e seguindo os seus próprios passos. Apesar de ela ter um histórico um pouco conturbado em sua vida política, Juliana Alves fez muitas ações e ocupou bastantes lugares na área.

No ano de 2015, foi vice-presidente de mesa da Câmara Municipal de Duque de Caxias, tendo sido a primeira mulher a ocupar este cargo. Presidiu a Comissão de Desenvolvimento Econômico da Indústria e do Comércio; foi vicepresidente da Comissão dos Direitos da Mulher, da Criança e do Adolescente, da comissão de Saúde e Assistência Social e da comissão de Educação e Cultura. Foi relatora da comissão de Finanças e Orçamentos; assumiu a posição de segunda suplente da comissão de Legislação, Justiça e Redação Final e também da comissão de Promoção e Igualdade Racial.

Juliana F. Alves participou de diversos eventos no decorrer de sua carreira política e sempre esteve envolvida em ações sociais de viés político da 


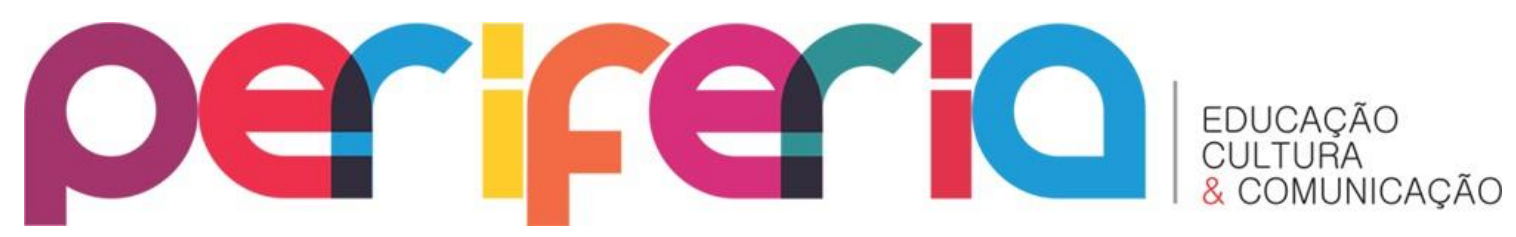

cidade, o que é compreensível já que ela foi vice-presidente da Comissão de Saúde e Assistência Social.

A ex-vereadora teve problemas passados com o Tribunal Superior Eleitoral (TSE), devido a acusações de troca de votos por remédios e de durante a sua campanha ter relações com demanda da prefeitura, como por o seu comitê eleitoral num prédio que pertencia a Fundação para o Desenvolvimento Tecnológico e Políticas Sociais de Caxias (FUNDEC). Porém esta fundação não pertence à prefeitura da cidade, apenas presta serviços de fomento social.

\section{CONSIDERAÇÕES FINAIS}

Ainda que essas mulheres tenham chegado a cargos políticos através do voto do popular, todas elas com exceção da parlamentar Dalva Lazaroni tiveram um homem por trás das suas ações até obterem determinado poder político.

Outra analise que trazemos é a de que todas as mulheres possuíam uma bagagem acadêmica que ia além da educação básica, mas mesmo com isso não conseguiram ganhar o reconhecimento e o mérito integral por suas ações, além de terem começado em secretarias antes de tornarem-se candidatas a algum cargo político.

A outra observação é referente a uma personagem que aparece por trás de várias mulheres que conquistaram o seu espaço na política de Duque de Caxias. Esta pessoa é o ex-prefeito Zito, que aparece como padrinho político de Estela Alves Vasconcelos (sua amiga e companheira de trabalho político) e Claise Maria (sua ex-esposa). Chamou-nos a atenção o envolvimento dele no ingresso dessas mulheres no meio político, além dele também ter sido padrinho de sua primeira ex-esposa, Narriman, que foi prefeita de Magé e de sua filha Andreia Almeida dos Santos Zito, que assim como Claise, também já foi deputada estadual pelo mesmo partido de seu pai.

Assim como Estela e Claise, Juliana do Táxi também teve um homem por trás de sua candidatura e que conseguiu fazê-la ganhar para vereadora da cidade, porém o diferencial é que ela consegue manter-se na vida política e assumir postos através dos contatos que criou no meio político. 




Com todas as observações feitas, chegamos à conclusão de que ainda no final do século $X X$ e meados do século XXI, a nossa política no município de Duque de Caxias ainda é patriarcal, ou seja, sempre precisa ter um padrinho político homem, ou seja, uma figura masculina por trás, para que as mulheres consigam conquistar o seu lugar neste meio.

Logo, o currículo acadêmico das mulheres, por exemplo, acaba sendo um diferencial, que pode favorecer a elas maior autonomia nas decisões futuras. Porém, o histórico pesquisado também evidenciou que o currículo educacional das mulheres políticas de Duque de Caxias era mais extenso do que o currículo de quem (figura masculina) optou por apoiá-las politicamente.

\section{REFERÊNCIAS}

BRASIL, do Jornal. Panorama das Eleições Municipais de Duque de Caxias. Disponível em: <http://www.jb.com.br/eleicoes2012/noticias/2012/04/10/panorama-das-eleicoes-municipais-de-duque-decaxias/ >. Acesso em 30 out. 2016.

CARVALHO, Liandra Lima. Estela, uma Estrela na Política de Duque de Caxias.

$<$ www.periodicoseletronicos.ufma.br/index.php/revistahumus/article/viewFile/3155

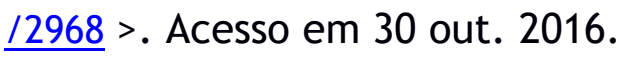

CARVALHO, Liandra Lima. Por trás de um grande homem, existe sempre uma grande mulher? Um estudo sobre as trajetórias políticas de duas ex-primeiras damas de um município da Baixada Fluminense. Disponível em:

<http://www.uel.br/eventos/gpp/pages/arquivos/GT6_Liandra\%20Lima\%20Ca rvalho.pdf >. Acesso em 30 out. 2016.

CARVALHO, Liandra Lima. "RESOLVI SER CLAISE MARIA PARA LUTAR POR VOCÊ:" UM ESTUDO DE CASO DO DAMISMO AO ATIVISMO POLÍTICO. Disponível em:

<http://www.revistagenero.uff.br/index.php/revistagenero/article/viewFile/ $\underline{657 / 403}>$. Acessado em: 30/10/2016.

HALL, Stuart. A identidade cultural na pós-modernidade. $7^{\mathrm{a}}$ ed. Rio de Janeiro: DP\&A, 2002. 


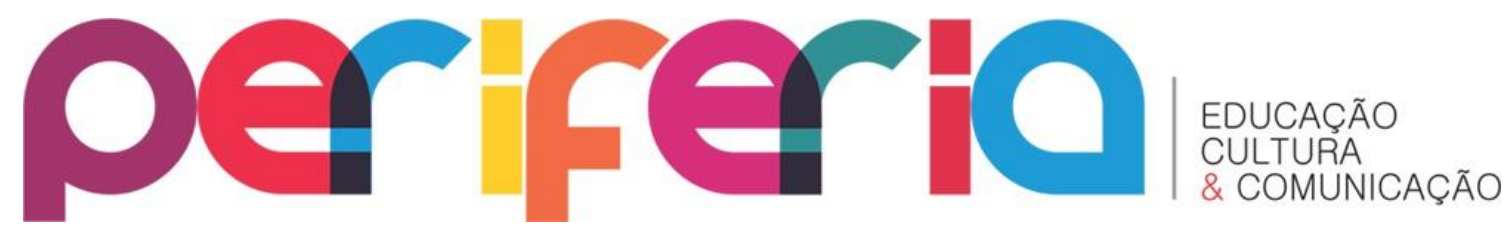

LANZARONI, André. Professora Dalva Lanzaroni, Nome Maior da Educação e da Cultura. Disponível em: <http://www.andrelazaroni.com.br/professora-dalvalazaroni-nome-maior-da-educacao-e-da-cultura/>. Acesso em 24 nov. 2016.

PAIVA, Fabiana. TSE deixa inelegível vereadora que distribui remédios em troca de votos. Disponível em: <https://extra.globo.com/noticias/extraextra/tse-deixa-inelegivel-vereadora-que-distribuiu-remedios-em-troca-devotos-19987050.html>. Acesso em 03 nov. 2016. 